Instructions for authors, subscriptions and further details:

http://qre.hipatiapress.com

\title{
List of Reviewers
}

Date of publication: February $28^{\text {th }}, 2021$

Edition period: February 2021 - June 2021

To cite this article: (2021). List of Reviewers. Qualitative Research in Education, 10(1), 115. doi:10.17583/qre.2020.7833

To link this article: http://dx.doi.org/10.17583/qre.2020.7833

\section{PLEASE SCROLL DOWN FOR ARTICLE}

The terms and conditions of use are related to the Open Journal System and to Creative Commons Attribution License (CC-BY). 


\section{List of Reviewers}

The Qualitative Research in Education journal thanks 2020 reviewers for their inestimable contribution to raise the quality standart of the journal. The journal wishes to convey special thanks to:

\section{Raúl A. Barba-Martín \& Aitor Gómez}

Editors

$\begin{array}{lll}\text { Acar-Erdol, Tuba } & \text { Flores Delgado, } & \text { Petri, Gábor } \\ \text { Aceituno- } & \text { Lizette Drusila } & \text { Rahmayanti, Henita } \\ \text { Aceituno, Pedro } & \text { Gairal, Regina } & \text { Raso Sánchez, } \\ \text { Adarkwah, Michael } & \text { Gallego Lema, } & \text { Francisco } \\ \text { Agyemang } & \text { Vanesa } & \text { Rayón-Rumayor, } \\ \text { Antão, Cećlia M. } & \text { González, Paúl } & \text { Laura } \\ \text { Azqueta, Arantxa } & \text { González- } & \text { Robertson, Dana A. } \\ \text { Betteney, Mark } & \text { Rodríguez, Diego } & \text { Rodríguez Herrero, } \\ \text { Bores García, Daniel } & \text { Grinberg, Silvia } & \text { Pablo } \\ \text { Bozkurt, Aras } & \text { Mariela } & \text { Sánchez, María Jesús } \\ \text { Cahill, Alex } & \text { Ibáñez, Nolfa } & \text { Sanz Simón, Carlos } \\ \text { Callus, Anne Marie } & \text { Lledó, Lourdes } & \text { Seiden, Jonathan } \\ \text { Christensen, Olivia } & \text { MacArthur, Kelly } & \text { Sisodiya, Sachin } \\ \text { Cowen, Robert } & \text { Rhea } & \text { Squires, Garry } \\ \text { Cubero, Javier } & \text { Majoko, Tawanda } & \text { Stenberg, Katariina } \\ \text { D’Ignazio, Tara } & \text { Martínez Lozano, C. } & \text { Suárez } \\ \text { Daumiller, Martin H. } & \text { Patricia } & \text { Pinéda, Marlén } \\ \text { Davidson, Rachel } & \text { Martínez-Prieto, } & \text { Tsuchiya, Shinsuke } \\ \text { Deltell Escolar, Luis } & \text { David } & \text { Vall-llovera, Montse } \\ \text { Dénervaud, Solange } & \text { Nisa, Titin Faridatun } & \text { Walters, William } \\ \text { Escanero- } & \text { Nutov, Liora } & \text { Wijnen-Meijer, } \\ \text { Marcén, Jesús F. } & \text { Obara, Samuel } & \text { Marjo } \\ \text { Feliu, Joel } & \text { Olson, Rebecca } & \text { Y1ldizll, Hülya } \\ \text { Fernández de Juan, } & \text { Eileen } & \text { Zapatera } \\ \text { Teresa } & \text { Otero, Fernando } & \text { Llinares, Alberto } \\ \text { Ferreira, Anita } & \text { Park, Gloria } & \end{array}$

